\title{
Early Childhood Teacher Education in the State of Kuwait: Hindrances and Challenges
}

\author{
Suad A T Noor (PhD) \\ Assistant Professor \\ Dept. of Educational Foundation \& Leadership \\ College of Basic Education (CBE) \\ Kuwait
}

\begin{abstract}
This paper examined the role of early childhood teachers' knowledge, beliefs and attitudes about learning/teaching process and the relationship to classroom practice. It critically explored the impact that a range of factors have on teachers' ability to implement practice that was consistent with their stated beliefs. This research revealed that various constraints related to the university context, to the nursery/kindergarten context and to the social-cultural context influenced their preparation as teacher in State of Kuwait. This paper is also based on a review of international and national research studies. The main issues addressed in this article are: teachers' pedagogical knowledge; beliefs, attitudes and teaching practice in the classroom.
\end{abstract}

Keywords: Early childhood education; teachers' education; teachers' role; teachers' knowledge; teachers' beliefs; teachers' attitude; challenges; Kuwait.

\section{Introduction}

Based on the analysis of the findings, this research theorizes that Early Childhood Education (ECE) and its teacher education are developed when teachers and trainees are provided with pedagogical content knowledge, and beliefs to improve the capabilities of early years teachers, and opportunities to interpret pedagogical knowledge, beliefs and attitudes into classroom practices to make the most of their capabilities. The findings revealed that teachers' and trainee teachers' knowledge, beliefs and attitudes are interlinked. Although trainee teachers' knowledge developed as a result of their learning, some of their beliefs about ECE in general seemed to remain stable over the period of their university course. The findings showed that trainee teachers' built their teaching identities on the wider social-cultural purposes of education in Kuwaiti society, which reflected expectations of their roles in society. The State of Kuwait gives a great deal of attention and seeks constantly, in all its plans, policies and strategies, to develop and modernize its educational systems. The country's long-term development plan (Vision 2035), places a strong emphasis on education as a catalyst to economic expansion, sustainable growth and social progress. Kuwait's strategy for the development of education (2005-2025) was a step on the path of development and modernization in which it focused on the importance of meeting the challenges posed by the nature of the age, in the forefront of which are globalization, and the demands of the information and technological revolution and openness to the world. A number of contemporary issues have been given particular attention, such as the use of technology in education and due care to democracy, respect for the constitution, respect for the opinions of others, pledging allegiance and loyalty and adherence to national identity with an openness to other cultures and taking advantage of its positive aspects. The Ministry of Education has given attention to diversifying education to include general and private education, the qualitative university education, professional and applied education. It also has given attention to training to raise the efficiency of teachers and developing their expertise and skills (MOE, 2005-2025).

The educational system in Kuwait is organized according to a general organization through which the trends of the educational process are specified as a prelude to achieving the philosophy and goals of education in Kuwait. The regulatory process is carried out by dividing the educational system into formal and non-formal education. Formal education is supervised by the Ministry of Education, it includes: 1) Public education; kindergarten, primary and secondary stages. 2) Qualitative education; this includes religious education, which concentrates on the Sharia sciences and Arabic language along with the subjects of general education; adult education and special needs education. 3) Private education: carried out in private schools, which are equal to the stages of general education. Non-formal education; is overseen by some government institutions and ministries, as well as some private institutions that provide training certificates. Besides that supervise this education are Kuwait University Centre for Community Service \& Continuing Education, the Public Authority for Applied Education and Training (PAAET), the Ministry of Awqaf and Islamic Affairs and Ministry of Commerce and Industry. 


\section{Challenges and Obstacles}

Teacher Education in the State of Kuwait is facing a set of challenges:

2.1 Political and Economic challenges: Kuwait lies on the Arabian Gulf, which is a globally important strategic location. It thus lies in an area of tension and continuing conflict due to the importance of its location and natural resources. Faced with this challenge, the people in charge of the educational system in Kuwait seek to accommodate all the variables and the facts surrounding it. Pursuing a democratic approach, education is entrenching principles of democracy and respect for the Constitution, laws and regulations through political education, curricula and behavioural practices as in the case of elections in schools and the teaching of some articles of the Constitution in the curriculum. Education also seeks to strengthen the education concepts of national unity and strengthen the spirit of citizenship, loyalty and belongingness to the homeland (MOE, 2005-2025). The State of Kuwait relies on one basic source of income, which is oil and it is being depleted. Therefore, it is permanently looking for alternative sources of income. Foreign investment experience and success is evidence of the value of other alternatives to the source or the specific statute. Therefore, Kuwait imports most of its needs and the majority of all goods, making the local markets is linked to global markets and affected negatively and positively. Educators also do not lose sight of consumer behaviour, which constitutes an economic challenge for education (MOE, 2005-2025).

2.2 Cultural and Social challenges: The cultural challenge is one of the most serious challenges because it is simply related to thought, the values and trends. Due to rapid changes, which are beginning to be felt in the lives of citizens regardless of the school, the government seeks to create leading and serious curricula about upholding national identity and consolidating positive values and the renunciation of negative ones, taking advantage of everything that is new and useful in cultures and global development. The Ministry of Education is seeking to absorb this challenge well in order to achieve its educational and humanitarian message.

To avoid social conflicts, the Ministry of Education has worked to eliminate tension and social conflicts wherever they are, by all available means, and developing the lasting sense of patriotism with an emphasis on learning social skills which are considered as one of the most important means of communication and cohesion among members of society (MoE, 2005-2025).

2.3 Technological and Cognitive challenges: Due to technological changes and developments all over the world, the Education Ministry is trying to take advantage of technology in the components of the educational system and the educational environment. The information revolution, or the explosion of knowledge, is one of the challenges facing education in our current age. Knowledge accumulation and accelerated scientific discoveries, in addition to severe partial specialties made those in charge of education search constantly for how to deal with them, so the Ministry of Education is seeking to take advantage of available knowledge, or make it functional, rather than just filling the minds of learners with information (MoE, 2005-2025).

The country has some more challenges, such as lack of effective regulatory and quality control, inadequate training of teachers, shortage of training and specialized academic programmes, shortage of early intervention programmes, and lack of strong public commitment.

\section{Early Childhood/Kindergarten Education}

Kuwait is a regional leader in preschool enrolment - Gross enrolment ratio (GER) at the preschool level is an impressive $66.4 \%$. Much of the concept of early childhood education has been subjected to Western values, beliefs and practices. However, it is essential to consider the different social context, political system and structure of education in every country, as well as societal and cultural beliefs about teaching children. The child is influenced by the type of care he/she receives from the family and also the other institutions in the society. He/she is also influenced by the type of education received when joining education institutions. Therefore, Kuwaiti society emphasises children and childhood and pays them attention because the children of today are the adults of tomorrow, investing in them is exactly an investment in the future, and the level of care offered to them by the State at the present time will have a positive impact on the future of Kuwait. Since the beginning of modern civilisation in the early 1950s, the State of Kuwait worked hard to provide appropriate housing for Kuwaiti families, mainly for the sake of the children. The State also provided them with health and prevention centres, built more kindergartens and equipped them with trained human resources and the latest equipment, and worked on enlarging the capacity of these kindergartens to accommodate the children. The five-year development plan 1984/85 - 1989/90 included projects for child care that represented an extension of this positive trend towards raising Kuwaiti children (Al-Mesh'an et al, 2001). The history of early years education in Kuwait can be divided into two phases, a period when it was not the concern of the government-a 'hands off' period, and a 'hands on' situation, with detailed prescription of what should be taught, and concern that teachers were under-performing. 
The history of kindergarten education started in 1954 when two kindergarten schools, Al-Mohalab and Tareq, were founded in Kuwait (Al-Ghafoor, 2004). The Kuwaiti pre-school system has undergone several changes since the 1950s and the education provided has been developed and improved. The Ministry of Education continues to make every effort to offer a better education to Kuwaiti children. For this purpose special buildings were constructed to achieve advanced international standards, and the curriculum of the kindergarten was subjected to continuous upgrading (AlGhafoor, 2004).

The number of kindergartens increased year after year due to the attention the State of Kuwait paid to the children of the age group prior to primary schooling and the number of children admitted to kindergartens has risen constantly. The attention paid to kindergartens in the State of Kuwait was represented in the content of the final report issued by the Sub-Committee for Preparing the General Education/ Kindergarten Draft Law. The report stated that Kindergarten in Kuwait is an education stage distinct from the other stages, which is supported by the State and supervised by the Ministry of Education; the State provides it with the necessary resources to carry out and realize its planned mission and objectives appropriately (Al-Hadhoud, 1993).

Besides, the kindergarten stage in Kuwait became vital due to the rapid social, economic, and cultural developments as well as the changes Kuwaiti society is experiencing. Moreover, continuity, support and development of this stage is considered a civilized phenomenon advocated by the contemporary educational and psychological studies in respect of the importance of early childhood and its impact on the future of both the individual and the society. Kindergarten in Kuwait has its own philosophy, which is based on four principles: to integrate the religious and social set-up; to meet the challenges of the global modern world; to fulfil the changing needs of Kuwaiti families; and to develop the personality of Kuwaiti children (Al-Mesh'an et al, 2001).

In Kuwait the pre-school system is divided into two sectors, state kindergartens and private kindergartens. Early childhood education, in the public sector, consists of two stages, KG1 and KG2, covering the ages 4 to 6 years. KG1 is for children aged 4 to 5 years, and KG2 is for children aged 5 to 6 years. Despite government schooling being readily available, many Kuwaitis choose not to send their children there, and instead enrol them in private schools. There are a number of private schools available and many have foreign sponsors and are co-educational. In Kuwait, the government does not wholly fund private education, although it is generously subsidized. The Kuwaiti Government pours more than $\mathrm{KD}^{1} 5.6$ million per annum into private educational facilities, in addition to allotting land for school construction and distributing textbooks (MOE, 2009).

Typically each classroom contains two teachers, a class teacher and an assistant teacher, although both hold the same qualification that is a bachelor degree, and the same salary. Each teacher is strongly affected by the schools' culture and philosophy. Pre-school education in Kuwait is not compulsory but free for all Kuwaiti citizens. Kindergartens strive to provide the appropriate conditions for the development of the child physically, mentally, emotionally, spiritually and socially, in accordance with the child's abilities and needs (UNESCO, 2010/11). The kindergartens in the fastergrowing private sector, are further divided into two groups: Arabic and foreign kindergartens. The latter have their own structure, curriculum and policy, depending on the educational system they follow and the country of origin and do not follow the Kuwaiti Government curriculum. The Statistics Department of Ministry of Education (2009) revealed that, during 2005 to 2009, despite the fee at British and American private kindergartens, the enrolment of Kuwaiti children in such kindergartens increased dramatically. Although there are many objectives of the kindergarten curricula in Kuwait, they can be classified into three developmental aspects: emotional aspects; psychological-motor aspects; and intellectual aspects. These objectives are translated into behavioural goals to be achieved through the various activities, experiences, beliefs and attitudes. It is imperative to discuss briefly the philosophy of early childhood education in Kuwait before describing the efforts to develop early childhood education.

\section{Objectives of Kindergartens in the State of Kuwait}

This philosophy had a great impact on forming the general objectives of kindergartens, which include developing the child's character in spiritual, mental, physical, emotional and social aspects, and providing him/her with skills that will assist in personality integration, according to the General Education Objectives document for kindergartens issued in 1982. Kindergartens aim to develop children's capacities for interaction and communication, encourage them to discover their environment, and provide them with social and moral guidance in a safe environment (UNESCO, 2006). The Kuwait Ministry of Education, (2007) set the objectives as follows:

1. To help children gain religious beliefs and ideas;

\footnotetext{
${ }^{1}$ Kuwaiti Dinar

180
} 
2. To assist the children in acquiring a sense of belonging; to their family, society, the Arabian Gulf, and the whole Arabian Islamic nation;

3. To promote strong self-esteem;

4. To help children acquire the means to be honest and positive in their relationships with adults;

5. To help children learn responsibility and independence, and learn the acceptance of living in a cooperative society;

6. To give children positive inclinations towards the environment surrounding them;

7. To help children become aware of their physical needs, keeping their bodies safe and healthy, to teach them to practise healthy habits in playing, relaxation, sleeping, eating, and dressing, and to assist them in learning the habits of security at home, outside, and within the kindergarten;

8. Developing all their senses;

9. Instilling some basic skills necessary for life; and

10. Expanding their interests and perceptions about the environment surrounding them, and also positive interaction. (MoE, 2007)

These goals are reflected in the kindergarten curriculum, which is presented in the following section.

\section{Curriculum of Early Childhood/Kindergarten Education}

The curriculum focuses on the role of guidance in the early years education. The curriculum is designed for those in the process of preparing to teach young children. The pre-school curriculum is designed with a strong focus on each individual child's total development in accordance with her/his modes of learning and creative self-development (Gahwaji, 2006). The pre-school aims include the provision of an educational environment that secures the balanced and integrated development of young children in all intellectual, social, psychological, and physical aspects. The emotional, moral and language aspects tended to be more emphasized. However, these aims explicitly stressed are preparation of younger children for future life in accordance with the challenges of this $21^{\text {st }}$ Century. The main philosophy of kindergarten in Kuwait is, 'Learn through Play'. According to this philosophy, the child should be free to develop intellectually, physically, socially and emotionally in a secure, interesting and motivating environment. Kindergartens aim to develop children's capacities for interaction and communication, encourage them to discover their environment, and provide them with social and moral guidance in a safe environment (UNESCO, 2010/2011; 2006). 'Children are taught about and through language, literature, arithmetic, natural science, music, art motor skills, role-play, and creativity' (Al-Hooli\& Al-Shammari, 2009: 388).

The early childhood curriculum is based on the scheme and philosophies of the National Association for the Education of Young Children (NAEYC), which gives children more freedom in the classroom (Al Shatti, 2011). The objectives of pre-school education in Kuwait are based on the Islamic religion. All of the children in KG1 commence their studies in Arabic. Islamic teaching is a basic and fundamental aspect of the kindergarten curriculum. Religious education also aims at initiating social tendencies and noble Islamic values such as: compassion, truthfulness, honesty, cooperation, work perfection, parents' obedience, cleanliness, helping the weak and observing the neighbour's rights. Moreover, Children begin by extending their vocabulary and learning songs and rhymes. Later in the KG2, they learn the letter sounds and begin to read and write in Arabic. This helps prepare Arab children for the Ministry Arabic curriculum, which begins in Year 1 of primary school and prepares the non-Arab students for their Arabic for Foreigners curriculum.

The children are encouraged to use their knowledge and skills in all other areas to solve problems, generate new questions and make connections across other areas of learning and development. Mathematics is a very important part of a child's development; therefore early years children should be exposed to a variety of mathematics-related experiences and materials. These activities include making sets, sorting, matching, classifying, making patterns and counting. All Numeracy work is of a practical nature in early years centres. There are arrangements in the schools for children to take part in physical education, which helps to develop co-ordination, control, movement and manipulation skills. The children learn basic ball skills, gymnastic skills, dance, athletics and how to work as a team. Music, Art, Role-play and Imaginative play are the main components of creative development. The music teacher has to play some instruments during the music class. Children are introduced to rhymes and songs related to their themes and intended to extend their language. Playing roles in Imaginative play is part of children's creative skills development.

The tendency is for social and emotional development to be studied together, as they are linked and reinforce one another (Palaiologou, 2010). This is an extremely important area of learning for early years children. It focuses on developing positive relationships with adults and other children, developing independence, developing a positive attitude to school and learning and feeling valued and admired. 
The early years in a child's life are very important to shape his/her personal, social and emotional development. These key issues are very important aspects of pedagogy in Early Childhood Education. At this stage the parents and teachers have a significant impact on children's well-being. The National Centre for Educational Development (NCED), a semiautonomous organization is currently involved in a number of initiatives and research studies based on the Kuwait context and related to the sustainable implementation of the 'Vision 2035'. Early childhood initiatives include a pilot project to use the Reggio Emilia model in kindergartens and also making kindergarten mandatory. For this purpose, 'a group of teachers from Kuwait's government kindergartens attended workshops to be trained in the Reggio Emilia model' (Winokur, 2014: 107)

\section{Methodology}

This qualitative study was carried out in 2016-17 in Kuwait. Fieldwork was conducted in the city of Kuwait. There were 45 in-depth individual interviews with university teachers, kindergarten teachers and trainee teachers. The majority of university teachers have doctorate qualification. Kindergarten teachers experience varied between 1 to 5 years. Three interview schedules were developed, each designed for specific category. Data for this study were collected during individual semi-structured interviews that were audio taped, transcribed, and subjected to qualitative analysis (Marton\& Trigwell, 2000). The meetings took place over a period of 3 to 4 months. Lasting approximately 45 minutes, interviews were audio-taped (with prior permission) and later transcribed. All participants were informed that their recordings would be transcribed in a written copy, and asked whether anyone had any objection. All the participants agreed to the procedure. Ethical aspects were considered throughout the study and protect the anonymity of all participants.

\section{Early Years Initial Teacher Training (EYITT) in Kuwait}

'In different places we have got economics, social transformation, personal development, religion, technology, ethics, and a shift in the teacher's role, all among the aims of teacher education'. (Perraton, 2001, p: 2). Researchers (Rodgers \& Raider-Roth, 2006; Grossman, 1990; Shulman, 1987; Wilson et al. 1987) claimed that professional preparation for trainee teachers is very important and teachers' professional knowledge has different categories to teach. FerriniMundy, et al. (2007) stated that there are two features of teacher education: 'the content knowledge of teachers and a well-articulated coherent curriculum' (p.311). Teacher education and training programmes need to move towards a, “conceptual change" approach, 'where teachers' experiences and beliefs are taken as the starting point for introducing new concepts or pedagogies' (Mansour, 2008:1629). In fact, the perceptions and opinions of teachers and trainees are affected by their beliefs and beliefs also influence their behaviour in the classrooms. However, it is difficult to demonstrate which teachers' behaviours are influenced by their beliefs (Deford, 1985).

The rapid changes we see in the world around us brought about by the forces of globalization and technological and cultural change often make it difficult to gauge what exactly it is our young children need to be learning in schools and how teachers are to be trained in order to prepare our children for the future. Teachers, however, are the motive power in education, so proper selection, training, retraining, and assuring their professional growth should receive high priority. Orientation courses for new teachers, refresher courses for all teachers after five years of services, seminars, extension lectures, permanent tenure, desirable work conditions and their participation in decision making are necessary to ensure their efficiency (MOE, 2012).

Teachers are required to have a bachelor's degree from the teacher training providers, where teachers can major in kindergarten education. There are two institutions in Kuwait to train the teachers: the College of Basic Education (CBE), which offers academic cultural and pedagogical training; and the Faculty of Education, at the University of Kuwait. Both institutions offer a four-year programme (eight semesters) leading to a bachelor's degree. The Faculty of Education (particularly teach training centre), Kuwait University, and the Basic Teacher Training College, at the Public Authority for Applied Education and Training, base preparation on a system combining specialized subjects and vocational training. The faculties accept applications that have obtained their Secondary General Certificate or those who have completed the curricula system. Educational programmes and plans in these faculties include three types of curricula: general culture curricula as required by the university; specialization curricula; and faculty or vocational curricula (UNESCO, 2010/2011).The College of Basic Education trains female graduate teachers mainly for kindergarten, primary school teachers, and other technical staff. The training programme of the College of Basic Education is divided into three areas:

- Cultural training, comprising 48 credit hours - 38\%- it consists of oral communication, writing skills in Arabic and skills in understanding and appreciating the Arab and Islamic culture;

- Academic training, comprising 40 credit hours - 32\%- this area comprises the knowledge and skills of pedagogy in the kindergarten stage; 
- Vocational training, comprising 38 credits - 30\%- this is the major requirement and covers the conceptual knowledge of different educational curriculums.

The Faculty of Education, University of Kuwait, offers three programmes for training kindergarten teachers, one programme for primary school teachers, another for training male and female teachers of intermediate and secondary schools, and two diploma-level programmes: diploma of pedagogical training; and diploma of pedagogical guidance (UNESCO, 2010/11)

\section{The Four Main Aspects of the Teaching and Teacher Training}

\subsection{Teachers' Knowledge \& Skills}

Lantolf and Thorne (2006) described that knowledge is considered to be constructed through a process of understanding rather than a product of the transmission of information. According to Al-Karanseh (2001), if teacher trainees are to be able to teach their students effectively, they must acquire different forms of knowledge during their professional preparation programmes, including, subject matter knowledge, pedagogical content knowledge, knowledge of classroom management, and knowledge of learners. Rovegno (1992) asserted that both content knowledge and pedagogical content knowledge affect early years teachers' practice in the classroom. According to Bennett (1993) trained teachers must attain sufficient subject knowledge in their specialist core subjects to teach and assess young children across the national curriculum. According to Shulman (2004) curriculum knowledge refers to the knowledge of the programmes, materials and resources designed for the teaching of early years learners. According to Rodgers and Raider-Roth (2006):In order for the teacher to be free to be present learning, it is necessary to have a deep knowledge of the subject matter, children and learning and a repertoire of pedagogical skills (from classroom management to lesson planning to curriculum design and execution of appropriate activities) (p. 279)

Haynes (2000) argued that teachers who work with early years children need an adequate knowledge of subject and an understanding of pedagogical strategies.

\subsection{Teachers' Beliefs}

Beliefs and perceptions are an important influence on pre-service teacher success in teacher education programmes as well as in the workforce, although little is known about those of students entering early years pre-service teacher programmes (Tschannen-Moran \&Woolfolk Hoy, 2001). Bandura (2006) believes that behaviour can be more effectively predicted by belief regarding capabilities than other measures of what individuals are actually able to accomplish. According to Richardson (1996), 'Attitudes and beliefs are a subset of a group of constructs that name, define, and describe the structure and content of mental states that are thought to drive a person's actions (p.102). Shaffer (2004) stated that beliefs are, 'an integrated system of personalized assumptions about the nature of the subject, the student, learning and teaching' (p.27). Pajares (1992) claims that, 'there is a strong relationship between teachers' educational beliefs and their planning, instructional decisions, and classroom practices' (p.326). Bennett et al. (1997) stated that early year teachers' beliefs about teaching and learning came from 'their personal and professional experiences, teacher education courses and personal life philosophies' (p.56). Erkmen (2010) asserted that teachers' beliefs 'come from their prior learning experiences as students, and teacher education courses' (p.29). In fact, teachers' teaching beliefs play a critical role in their everyday teaching practices. The following section explore where teachers attitudes came from.

\subsection{Teachers' Attitudes}

According to Burns (1997) attitudes are 'evaluated beliefs which predispose the individual to respond a preferential way' (p.456). Rivalland (2007) claimed that beliefs and attitudes are socially and culturally constructed, deeply seated, resistant to change, and central to our way of thinking, doing and being. 'Attitude being a social construct is influenced by many factors like gender social strata, age, stream of education and previous experience of the job' (Bhargava\&Pathy, 2014: 27). Attitude is made up of three components: 1) the affective component: feelings towards the object; 2) the behavioural component: which is the action taken towards the object; and 3) the cognitive component: which is the knowledge about an attitude object; hence acts as a yardstick of the individual behaviour (Feldman, 2002). According to Rokeach (1968) behaviour is a function of two attitudes: attitude towards an object and attitude towards a situation. Teaching, being a dynamic activity requires a favourable attitude and certain specific competencies from its practitioners. A positive attitude helps the teacher to develop a conducive learner-friendly environment in the classroom. Teacher training programmes help in shaping the attitude of trainee teachers toward the teaching profession. Early years/Preparatory teachers bring a multifaceted range of beliefs and attitudes to teaching. The early years teachers' attitudes towards the teaching/learning process focused on, how they interacted with young children. Their beliefs and attitudes affected their teaching and behaviour towards students, and job satisfaction from their work. Devi (2005) stated that success in the teaching field depends upon two main factors: attitude towards profession; 
and job satisfaction. The attitude, interest and behaviour of early years teachers help in shaping the personality of the student. There are five factors identified by Bhargava and Pathy (2014), which 'affected the attitude of the teachers: domestic environment; family background; socio-economic background; beliefs; and educational institutes' (p: 27). Kilgallon (2006) stated that, 'maintaining a positive attitude and utilizing intrinsic motivation empowered nearly half of early childhood teachers in this study to become proactive, seek information and engage in acts of collaboration'.

\subsection{Teaching Practices/Pedagogy}

This section discusses the two aspects of teaching; the teaching practice during early years ITE training programmes; and actual classroom practice. Practice has been described in the literature as being observed (Smith \& Shepard, 1988). Elliot (2005) argued that reflective practice is an important part of professional preparation, in which student teachers themselves are reflective about their own teaching abilities and children's learning outcomes. Students without any experience of teaching practice do not connect the teachers' activities to the reality of the classroom (Leijen, et al. 2013). 'Unreal optimism' based on the acquired knowledge is characteristic of a trainee teacher, beginning their teaching practice at school (Pajares, 1992). Carpenter and Blance (2007) believe that teaching practice provides opportunity for developing a three-way partnership between the university, the school and teacher trainees. This partnership is collaborative, neutrally advantageous and shares governance and evaluation of the programme. The trainee teachers preferred practices that were aimed at mechanical achievement, and gain real world experience within a school culture where they can develop a range of personal and professional attributes. They develop awareness of a workplace culture and the fluidity of the rapidly changing world.

The practicing teachers' choices of teaching practices were aimed at developing the pupils' learning competences and the implementation of competence-based tasks, and have opportunity to develop professionally as they serve as mentors, teacher leaders and co-researchers to cohorts of teacher trainees. Laursen (2007) stated that, ' many student teachers experience problems about the relationship between 'theory' and 'practice' in teacher education and find 'theories' irrelevant to the development of teacher competencies'. There is a challenging link between theory and practice and that educational theories are not easily applied into classroom practices (Alzaydi, 2010). According to Alzaydi (2010: 64), 'practice needs theory which provides it with principles and guidelines'. One of the main findings of this study was that the teaching practice or trainees' experience had helped trainee teachers to gain a better understanding of the role of a teacher. The study in general evidenced that the implementation of teaching programme by early childhood teachers improved their ability to cope with the demands of their work (Kilgallon, 2006).

\section{Findings}

In Kuwait the minimum requirement for study in the pre-service teacher education programmes is the Secondary School Certificate and the ITE programmes require four years to gain a Bachelor degree in Early Childhood Education (MOE, 2009) Analysis of data obtained shows that in Kuwait there is a lack of educational policies, particularly policies for early years/kindergarten education and teacher training. There is poor implementation of existing policies due to disorganized implementation strategies. The educational system is centralized in Kuwait and this has an enormous impact on the development of teacher training programmes. The centralization of administrative activity is marked in terms of funding to the universities and decision-making about curriculum and scholarships. In Kuwait, universities are dependent on governmental funding and must follow on early years curriculum is designed by the Ministry of Education. The curricula are inflexible, with a strict span of time, and this influences the quality of teacher education and training. The study also found that there is a lack of in-service teacher training programmes and professional development of early years teachers.

The study indicates that in Kuwaiti universities inadequate management and lack of supervision and accountability practices are some of the major issues that need to be appropriately addressed in the early years teaching programmes, and these programmes lack the institutionalized arrangements for providing proper training or guidelines to teacher educators in universities. Kuwaiti education system is lacking in effective partnership between schools and universities in terms of early years teacher education and training. The majority of trainees felt that there is a lack of connection between the theoretical knowledge they learn in kindergarten teacher training programme and the school-based teaching practice and experiences. The knowledge and beliefs of the majority of trainee teachers were influenced by prominent educational theories, for example, Piaget, Froebel, and Vygotsky. The evidence presented in the literature review showed that Western educational systems have moved away from Piagetian theories and Froebel's concepts in the last three decades and worked towards Vygotskian theory or post-Vygotskian theories (for example, Bruner, 1996) which emphasized the role of culture and social interactions in developing children's knowledge and skills. Unlike Piaget, Vygotsky did not limit children's learning and development to age-related stages. 
In this research, the early years teachers indicated that their actions and reactions during the daily demands of their work were determined by the attributes (beliefs, attitudes, and emotions) of their human nature, which they had inherited from their earlier life experiences, and strongly shaped by cultural, religious and social beliefs.The majority of trainee teachers thought that the early years teacher training programme at their institutes prepared them adequately to plan their work and build their confidence as teachers. They also revealed that they had received adequate preparation in the content and pedagogical aspects. These programmes enhanced their knowledge and experience with regard to the development of children, which they did not know about before. The teaching training programme prepared the student teachers to interact effectively with the children around them. Most of the trainees stated that their course providers had adequate resources, for example, physical facilities and educational resource materials. They also mentioned that the teaching programme provides educational activities and different programmes that benefit young children. They also mentioned that they understood how a kindergarten teacher could be trained differently from the other kinds of teachers.

However, the analysis shows that beginning teachers are not adequately prepared in the methodological aspects, student-centred teaching, and children with special needs. In this context, the early years teacher training programme neither prepared the teachers theoretically nor provided them with adequate practical experience. According to a practising kindergarten teacher, teaching approaches learned during pre-service teaching practice are more beneficial than theoretical approaches and she suggested the Ministry of Education should increase the duration of teaching practice. This study also indicates that beginning teachers did not get sufficient opportunity to reflect on their efforts during practice teaching due to its short duration, which is only 12 weeks. This reflects that the teacher training curriculum is more theoretical and places very little emphasis on practice teaching. It shows a significant gap between theories taught in the universities and actual classroom practice. Laursen (2007) portrayed a similar situation in the words of trainee teachers, also claimed that members of the teaching staff at the university did not care about how educational theories are linked to classroom practices. He (2007) similarly argued that, 'many student teachers experience problems about the relationship between 'theory' and 'practice' in teacher education and find theories irrelevant to the development of teacher competences' (The Biannual ISATT Conference, 5-9 July 2007).

A teacher training programme in Kuwait is needed which will transform teachers' beliefs and behaviours towards children's cognitive, emotional and physical development. The trainee teachers built and developed their content pedagogical knowledge during the years of preparation as early years teachers. This was especially enhanced through teaching practice in on authentic setting situation (in schools). The trainees' content pedagogical knowledge was influenced by the dominant ideas based on universal (Western) ideas about teaching practice with young people and reflect also the cultural approaches and values within Kuwait. The study revealed that trainee teachers were aware of their increasing knowledge during the programme and this improvement comes gradually year after year. They understood the difference between their knowledge before starting the programme and after moving forward. They had also gained knowledge about planning appropriate activities for children and how to handle their educational and behavioural problems. The trainee teachers were anticipated to develop and relate three kinds of knowledge: 1) content knowledge (what to teach); 2) pedagogical knowledge (how to teach); and 3) conceptual knowledge (why to teach). The participants understood the importance of pedagogical knowledge in order to begin actual teaching practice. There was a difference of opinion about professional knowledge, due to participants' prior knowledge, beliefs, experiences and cultural values regarding teaching and learning. Almost all participants felt that their knowledge about kindergarten education and its teacher education has progressed and grown, and according to them, this was due to the courses and modules taught during their teacher preparation programmes. They mentioned that they had no prior knowledge about child psychology, but by completing this course they had learned many things about children psychology, which they thought would be very helpful during their future life. They also believed that every year they discovered new knowledge and new experiences during the teacher training programme and during their teaching practice.

It was found that all participants considered they had the knowledge to design educational activities that they understood the content of the curriculum of pre-school education and they were applying their knowledge in reality during their classroom practice. The teachers confirmed that they had 'meta-cognitive' knowledge and understanding of the curriculum. Moreover, the kindergarten teachers also believed that children learn through play and direct experiences; for example, a visit to the zoo, parks and exhibitions for young children enhance their knowledge and learning ability. The participants also stated that telling stories and singing educational songs (for example, about animals, numbers etc.) is also a very impressive way of teaching to young children.

The study revealed that Kuwaiti trainee teachers tried to adhere to the traditional Muslim culture and values during their teaching and their Islamic beliefs were reflected in the national curriculum of Kuwaiti kindergarten education. Therefore, it can be argued that the purpose of early years education in Kuwaiti society is related to the beliefs of teachers, either Islamic or traditional. 
In fact, the beliefs of teachers and student teachers were very similar in general, due to their coming from the same culture and same country. The experiences and personal religious beliefs of Kuwaiti teachers and trainees shaped their beliefs and identities, and also affected their practices and teaching orientation in their early years classroom (Mansour, 2008). The study revealed that trainee teachers and working teachers bring their beliefs to the teacher training programmes and early years classrooms. Teachers' beliefs and their practices are influenced by the social and cultural context, as contextual factors form and influence the beliefs of teachers and trainees and these beliefs affect teachers' practices. The beliefs of teacher trainees were closely linked with their interest and motivation to become kindergarten teachers and were similar in general. That was because all the participants were from the same city and country. Changes in the beliefs of teachers were reported after experiencing the actual teaching in the classroom.

The study revealed that there was a substantial difference in attitudes of trainee teachers toward the teaching profession, before starting the early years teaching programme and after completing the course. The study found that those student teachers, whose parents were teachers had more positive attitude towards teaching profession. The kindergarten teachers generally showed high levels of feeling of competence and self-efficacy about teaching to young children. Almost all teachers and trainees expressed their interest in the teaching profession, especially teaching to kindergarteners and their enjoyment when teaching to young children was evident. These high task values of teachers may have positive effects on children's learning and development. They recognized teaching as having more of a focus on children than on content. The majority of respondents were convinced that kindergartners needed to consider the classroom as a, 'home away from home'. The current study also observed that teachers focused on improving the sentiments and providing children with skills and experiences that could contribute to reinforce their personality. According to them, the intelligence and capabilities of children should be treated with care and real experience. Some interviewees' claims recalled Maxim's (1985) view that teaching is more than conveying knowledge and good attitudes towards learning, but includes, 'modelling creative behaviour', to help to promote creativity in each child.

All participants recognized the importance of kindergarten teaching and its teacher training. The teacher trainees believed that the teachers' training programme enhanced their confidence with regard to teaching. The majority of trainee teachers stated that they had developed their understanding of pedagogical knowledge and effective teaching strategies during their teaching practice in real classroom situations. However, there was still discontinuity between good teaching practice and the real classroom. One of the important findings of this study was that trainee teachers thought they needed more visits to kindergartens during their teachers training programme in Kuwait, for the better quality of teaching in kindergartens. Cheng (2005) argued that student teachers should have regular visits to a variety of kindergartens to develop gradually their understanding of the kindergarten context and their role as a teacher. The study also revealed that during actual teaching, some teachers were unable to interact very well with the young children, due to the short term (three months) of teaching practice during the training programme. This shows that trainees need more time for teaching practice in kindergartens to improve their teaching activities according to the children's knowledge and abilities.

According to the kindergarten teachers, theory is different from actual practice. They stated that, in many respects, they are unable to follow theory. The majority of participants recognized that kindergarten teachers have a distinctive identity, in terms of their qualifications, characteristics, and understanding of young children's emotional, psychological and physical developments. They thought this quality made them distinguished from other primary and secondary school teachers. The study evidenced that more experienced kindergarten teachers had very positive relationships with young children.

The study revealed that early years teachers were critical about the teaching practice during the early years teacher education programme and during their actual practice in the classroom. According to them, there were some inconsistencies between their teacher training and experience of teaching in kindergartens. In fact the classroom situation was different from the theories they learned during their teacher training. According to the interviewees the teacher-training programme did not cover the actual core of the early years curriculum. The teachers and student teachers supported Pajares' (1992) description of a strong relationship between teachers' beliefs, their content pedagogical knowledge and classroom practice.

The majority of kindergarten teachers and trainees indicated that their knowledge and learning about the curriculum of the kindergarten module was very useful for preparing them to teach young children: for example, cognitive development, emotional development, social development, psychological development and mental development. Since Islam governs the way of life in Kuwait, the pre-school curriculum and pedagogy are constructed mainly according to the teachings of Islam. Both the teachers and trainee teachers introduced religious teaching and values to children through short stories of prophets and initial acts of worship. 
According to the collected data, the teachers learned about the different stages of development, for example, the physical growth of children and their ability to develop their characteristics. During their teaching service the kindergarten teachers developed their abilities to plan different physical activities for children and provide them with the appropriate educational equipment for the activity. The student teachers stated that they needed to know more about the kindergarten curriculum through the content taught at the universities and through the practices in actual classrooms.

The study indicated that the kindergarten curriculum provides teacher with titles of different themes and requires teachers to look for content that fits each theme and to implement its objectives and using a variety of sources of knowledge. However, the trainee teachers needed more visits to kindergartens during their four years of study to implement the above elements of curriculum practically. In fact, the trainee teachers' learning should be based on the authentic setting and problems that they encounter in the classroom (Moswela, 2006). Therefore, Kuwaiti trainees demanded that the early years teaching programme should include more time for the practical element enable them to understand the main aspects of pre-school curriculum.

\section{References}

Al-Ghafoor, Y. F. (2004).Status of kindergarten in the State of Kuwait ( ${ }^{\text {nd }}$ Edition). Kuwait: Al-Faisal Press

Al-Hadhoud, D. A. (1993).Introduction to early education: pre-school education. NahdatMasr Publishing and Distribution House.

Al-Hooli, A. \& Al-Shammari, Z. (2009), Education, 129 (3): 382-399. http://www.researchgate.net/publication/234671665

Al-Karanseh, S. (2001), Participants' perspectives of initial social studies teacher preparation in Jordon. Unpublished $\mathrm{PhD}$ thesis. University of Exeter, UK: Exeter

Al-Mesh'n, M. A.; Al-Essa, A. A.; Al-Hajeri, K. F.; Al-Amairi, S. R.; (2001) Teacher's guide: for education experiences in kindergartens second level. Ministry of Education: Educational Researches and Curriculum Sector. Kuwait.

Al Shatti, H. (2011), Parents' perspectives of government and private kindergarten systems in Kuwait. ARCELS. 8: 124

Alzaydi, D. A. (2010), Activity theory as a lens to explore participant perspective of the administrative and academic activity systems in a university-school partnership in initial education in Saudi Arabia. Unpublished $\mathrm{PhD}$ Thesis, University of Exeter, UK

Bandura, A., (2006), Adolescent development from an agented perspective. In F. Pajares and T. Urdan (Eds.), SelfEfficacy beliefs of adolescents (pp. 1-44). Connecticut: Information Age Publishing.

Bennett, N., Wood, L., \& Rogers, S. (1997), Teaching through play. Buckingham: Open University Press

Bennett, J. (2004), Curriculum issues in national policy making, Paris: OCED.

Bhargava, A. \&Pathy, M. K. (2014), Attitudes of student teachers towards teaching profession. Turkish Online Journal of Distance Education- TOJDE. ISSN 1302-6488, 15 (3): 27-36

Burns, R. (1997). Introduction to research methods (3rd ed.).Melbourne, Vic.: Addison Wesley Longman.

Carpenter, L. \&Blance B. (2007), Teaching internship and the learning community in Townsend \& Bates R. (Eds.) Handbook of Teacher Education. Griffith University.

Cheng, M. (2005), Understanding Teacher professional development during the field experience period using a sociocultural view of learning. Teacher Development, 9 (3): 347-368.

Deford, D. E. (1985), Validation the construct of theoretical orientation in reading instruction. Reading Research Quarterly, 20: 350-367.

Devi, U. V. K. (2005), A study of role conflict, job satisfaction and select presage variables discriminating between successful and less successful secondary school women teachers of Kerala. Unpublished $\mathrm{PhD}$ Thesis.University of Calicut.

Elliot, D. C. (2005), Teaching on target: models, strategies, and methods that work. London: Corwin Press.

Erkmen, B. (2010), Non-native novice EFL teachers' beliefs about teaching and learning. PhD Thesis. Nottingham, UK: University of Nottingham

Feldman, A. (2002), Existential approaches to action research. Educational Action Research, 10 (2): 233-251.

Ferrini-Mundy, J. Burrill, G. \& Schmidt, W. H. (2007), Building teacher capacity for implementing curricular coherence: mathematics teacher professional development tasks. Journal of Mathematics Teacher Education, 10(4-6): 311-324. 
Grossman, P. L. (1990), The making of a teacher: teacher knowledge and teacher education. New York: Teachers College Press.

Gahwaji, J. M. N. (2006), Designing a tool for evaluating the quality of pre-school education in Saudi Arabia. An unpublished Doctoral Thesis. University of Exeter

Haynes, M. (2000), Teacher education for early childhood through the New Zealand curriculum framework.New Zealand Research in Early Childhood Education, 3: 163-176.

Kilgallon, P. (2006). The sustainment of early childhood teachers in the classroom. Unpublished Doctoral Thesis: Edith Cowan University

Lantolf , J., \& Thorne, S. (2006), Sociocultural theory and the genesis of second language development, (Oxford: OUP)

Laursen, P. (2007), Student teachers' conceptions of theory and practice in teacher education.The Biannual ISATT Conference, 5-9 July 2007, Canada: Brock University.

Leijen, Ä., Kullasepp, K., \&Ots, A. (2013), Investigating the internalization of professional role expectations among pre-service teachers.Estonian Journal of Education, 1: 72- 96.

Mansour, N. (2008), The experiences and personal religious beliefs of Egyptian science teachers as a framework for understanding the shaping and reshaping of their beliefs and practices about Science-Technology- Society (STS). International Journal of Science Education, 30(12): 1605-1634.

Maxim, G. (1985), Creative: encouraging the spirit of wonder and magic. In G. W. Maxim (Ed.), The very young, (pp. 359-402). Belmont, California: Wordsworth Publication Company

Ministry of Education, (2007), Kindergarten teacher guidebook. Kuwait: Ministry Press

Ministry of Education, (2009) Statistical information for the years 2005 to 2009.Kuwait, Department of Private Education. Ministry Press

Ministry of Education, (2012), Educational statistical group 2012-1011.Available at: doc.iiep.unesco.org/wwwisis/repdoc/E032325_2011.pdf[Accessed January 2016]

Moswela, B. (2006), Teacher professional development for the new school improvement in Botswana.International Journal of Lifelong Education, 25 (6): 623-632

Pajares, M. F. (1992). Teachers' beliefs and educational research: cleaning up a messy construct. Review of Educational Research, 62(3): 307-332.

Palaiologou, I. (2010), The early years foundation stage: theory and practice. Sage Publishers: London

Perraton, H. (2001), 'Quality and standards of INSET teacher training by open and distance learning'. Paper presented to the Pan-African Dialogue on in- service teacher training by open and distance learning, Windhoek Namibia.

Richardson, V. (1996), The role of attitudes and beliefs in learning to teach.In J. Sikula (Ed.) Handbook of research on teacher education. New York: Macmillan

Rivalland, C.M.P. (2007). When are beliefs just 'the tip of the iceberg'? Exploring early childhood professionals' beliefs and practices about teaching and learning. Australian Journal of Early Childhood, 32(1): 30-37

Rodgers, C., \& Raider-Roth, M. (2006), Presence in teaching.Teachers and Teaching: Theory and Practice, 12 (3): 265-287.

Rokeach, M. (1968). Beliefs, attitudes, and values: a theory of organization and change. San Francisco: Jossey-Bass.

Rovegno, J. C. (1992), Learning to teach in a field-based methods course: the development of pedagogical content knowledge. Teaching and Teacher Education, 8(1): 69-82.

Shaffer, K. G. (2004), Two high school teachers' initial use of geometer's sketchpad: issues of implementation. Unpublished PhD Thesis. Michigan: Western Michigan University.

Shulman, L. S. (1987). Knowledge and teaching: foundations of the new reform. Harvard Educational Review, 56(1): $1-21$

Shulman, L. (2004), The wisdom of practice. USA: Jossey-Bass.

Smith, L., \& Shepard, M., (1988b), Kindergarten readiness and retention: A qualitative study of teachers' beliefs and practices. American Educational Research Journal, 25(3): 307-333

Tschannen-Moran, M., \&Woolfolk Hoy, A. (2001), Teacher efficacy: capturing an elusive construct. Teaching and Teacher Education, 17: 783-805.

UNESCO, (2006). Kuwait: Early childhood care and education (ECCE) programmes. UNESCO International Bureau of Education: Geneva UNESCO, (2010/2011), World data on education. $7^{\text {th }}$ Edition. Kuwait: UNESCO

Wilson, S. Shulman, L., \& Richert, A. (1987), 150 different ways of knowing: representations of knowledge in teaching. In J. Calderhead (Ed.), Exploring teachers' thinking(pp. 104-124). London: Cassells

Winokur, I. K. (2014), From centralized education to innovation: cultural shifts in Kuwait's education system. In A. W. Wiseman; N.H. Alromi; \& S. Alshumrani, Education for a knowledge society in Arabian Gulf countries. UK: Emerald Group Publishing Ltd. 103-126 